Short communication

\title{
Evaluation of KIM-1 as an early biomarker of snakebite-induced AKI in mice
}

\author{
Rodrigo Tavares Dantas ${ }^{\mathrm{a}}$, Tiago Lima Sampaio ${ }^{\mathrm{a}}$, Dânya Bandeira Lima ${ }^{\mathrm{b}}$, \\ Ramon Róseo Paula Pessoa Bezerra de Menezes ${ }^{\mathrm{a}}$, Jader Almeida Canuto ${ }^{\mathrm{b}}$, \\ Marcos Hikari Toyamac ${ }^{c}$, Janaína Serra Azul Monteiro Evangelista ${ }^{\mathrm{d}}$, Alice Maria Costa Martins ${ }^{\mathrm{b}, *}$ \\ a Departamento de Fisiologia e Farmacologia, Universidade Federal do Ceará, Fortaleza, Ceará, Brazil \\ b Departmento de Análises Clínicas e Toxicológicas, Universidade Federal do Ceará, Fortaleza, Ceará, Brazil \\ ${ }^{\mathrm{c}}$ Unidade de São Vicente, Campus do litoral Paulista, Universidade do Estado de São Paulo (UNESP), São Paulo, Brazil \\ a Programa de Pós-Graduação em Ciências Veterinárias, Faculdade de Veterinária, Universidade Estadual do Ceará, Fortaleza, Ceará, Brazil
}

A R T I C L E I N F O

\section{Keywords:}

Bothropic envenomation

KIM-1

Bothrops insularis venom

Acute kidney injury

\begin{abstract}
A B S T R A C T
Acute kidney injury (AKI) is one of the most important complications of bothropic poisoning and its early identification remains challenging. The nephrotoxicity of Bothrops insularis venom (BinsV) was previously described by our research group. In this study, we continued to evaluate the effect of BinsV on kidney function in mice and LLC-MK2 proximal tubule cells, evaluating KIM-1 protein as an early AKI biomarker. Male Swiss mice were inoculated with BinsV intramuscularly and observed for $24 \mathrm{~h}$ in a metabolic cage model. Urine and blood were collected for biochemical analyses and the kidneys were examined for oxide-reducing balance and submitted to histological analysis. LLC-MK2 cells incubated with BinsV were assessed for cell viability and cell death mechanism by flow cytometry. Histological analysis of the kidneys indicated AKI and the oxide-reducing analyses demonstrated a decreasing in reduced glutathione (GSH) levels and an increasing on Malondialdehyde (MDA) levels. BinsV was cytotoxic to LLC-MK2 and the cytometry analyses suggested necrosis. Within $24 \mathrm{~h}$ after the envenomation, urinary creatinine did not increase, but the urinary levels of KIM-1 increased. In conclusion, we found AKI evidence in the kidney tissue and the increase in the KIM-1 levels suggest it can be used as an early AKI biomarker.
\end{abstract}

\section{Introduction}

Annually, there are many cases of snake envenomation in Brazil, most of them associated with the Bothrops genus (Queiroz et al., 2008). The venom of Bothrops insularis, commonly known as the golden lancehead or jararaca-ilhoa has similar characteristics to that of other Bothrops species, causing local damage and systemic lesions, with a fourteen-fold greater potency (Valente et al., 2009). Systemic complications occur in the absence of or late antivenom administration, leading to more severe cases associated with intense bleeding, shock and Acute Kidney Injury (AKI), which are closely related to death (Sgrignolli et al., 2011).

AKI is a serious complication, which has devastating short- and long-term consequences. Despite standardization of AKI definition and staging, the kidney function marker is the serum creatinine level, which is unspecific and later, so the early identification remains challenging. Furthermore, the delay in serum creatinine level increase after glomerular filtration loss also impairs the detection of decreased kidney function in patients with AKI. During the past decade, numerous clinical investigations have evaluated the usefulness of several biomarkers in AKI early diagnosis and risk stratification (Vijayan et al., 2016).

Kidney injury molecule-1 (KIM-1, also named TIM-1 and HAVCR-1) was identified as the most highly upregulated protein in the renal proximal tubule after injury. It is a type- 1 membrane protein of which ectodomain is released into the tubule lumen. The ectodomain is heavily glycosylated and stable and appears in the urine after the injury (Bonventre, 2014). B. insularis venom has been reported and characterized by its nephrotoxic effects on renal distal tubular epithelial cells (Mello et al., 2014) and kidney in situ (Braga et al., 2006, 2007, 2008). The nephrotoxicity caused by Bothrops venom in vivo was evaluated in this study, as well as the cytotoxicity in renal proximal tubular epithelial cells, aiming to evaluate KIM-1 as an early biomarker of snakebite-induced AKI in mice.

\footnotetext{
* Corresponding author.

E-mail address: martinsalice@gmail.com (A.M.C. Martins).
} 


\section{Methods}

\subsection{Animals and Bothrops insularis venom}

The experimental protocol was approved by the Ethical Committee on Animal Research of Federal University of Ceara (UFC) (n. 40/2016) in accordance with the ethical guidelines. Male Swiss mice, obtained from the central vivarium of UFC, weighed $18-22 \mathrm{~g}$, and were maintained under controlled conditions $\left(25 \pm 2{ }^{\circ} \mathrm{C}\right.$ ambient temperature, $12 \mathrm{~h}$ light-dark cycle). Food and water were offered ad libitum. B. insularis venom (BinsV) was kindly donated by Dr. Marcos H. Toyama, from Universidade Estadual Paulista (UNESP).

\subsection{Experimental procedure}

Swiss mice (18-33g, twelve: six for group) where lightly anesthetized with ether and injected intramuscularly (i.m.) in the gluteus, with $3.5 \mathrm{mg} / \mathrm{kg}$ of BinsV and observed for $24 \mathrm{~h}$ in a metabolic cage model. The venom was previously diluted in sterile saline. Mice injected in the same muscle with saline were used as control. During the $24 \mathrm{~h}$, urine samples were obtained through a metabolic cage. At the end of this period, animals were anesthetized with Thiopental (Cristália Pharmaceutical and Chemical, São Paulo, Brazil) (50 mg/kg i.p.) to obtain blood samples for biochemical tests. Additionally, the left kidneys were collected for histological evaluation. Euthanasia was performed on anesthetized animals by administration of saturated solution of potassium chloride intravenously, as described by the ethical guidelines.

\subsection{Histological analysis}

The removed renal tissue was placed in a $10 \%$ solution of buffered formaldehyde and $24 \mathrm{~h}$ later, it was transferred to a $70 \%$ ethanol solution. After tissue processing, $3 \mu \mathrm{m}$ median-sagittal paraffin sections were stained with hematoxylin-eosin for histological evaluation.

\subsection{Determination of TBARS levels}

For tissue analyzes, the left kidney was removed and symmetrically divided with a scalpel. One half was submitted to histological analysis and the other was fully used to produce the homogenate for oxidative stress analysis. The samples were kept in an ice bath. The homogenization was performed cautiously aiming to prevent overheating and overexposure to atmospheric air and light. Malondialdehyde (MDA) levels in kidney tissue were determined as an indicator of lipid peroxidation, as previously described, using the Thiobarbituric Acid Reactive Substances (TBARS) method (Mihara et al., 1980). Fragments of the left kidney were homogenized with $1.15 \% \mathrm{KCl}$ in an ice bath, followed by the addition of $1 \%$ phosphoric acid and $0.6 \%$ thiobarbituric acid. The mixture was incubated at $96^{\circ} \mathrm{C}$ for $20 \mathrm{~min}$. Absorbance was measured by spectrophotometry at $532 \mathrm{~nm}$ (Asys UV 340, Biochrom, Cambridge, UK). The results were expressed in $\mu \mathrm{g} / \mathrm{g}$ of tissue.

\subsection{Determination of GSH levels}

For the determination of reduced glutathione ( $\gamma$-glutamy-l-cysteinylglycine, GSH) levels, a homogenate was prepared with $0.02 \mathrm{M}$ EDTA in an ice bath. The samples were mixed with $50 \%$ trichloroacetic acid, centrifuged (30 $00 \mathrm{rpm}, 15 \mathrm{~min}$ ), and $400 \mu \mathrm{L}$ of the supernatant was added to $800 \mu \mathrm{L}$ of Tris- $\mathrm{HCl}$ buffer (0.4 M, pH 8.9) and $20 \mu \mathrm{L}$ of DTNB (5,5 -dithiobis-(2-nitrobenzoic acid)). Finally, the absorbance was measured by spectrophotometry at $412 \mathrm{~nm}$ (Asys UV 340, Biochrom, Cambridge, UK). The results were expressed in $\mu \mathrm{g} / \mathrm{g}$ of tissue.

\subsection{Measurement of biochemical parameters}

Blood samples were collected in tubes containing lithic heparin, and then centrifuged ( $4500 \mathrm{rpm}$ for $10 \mathrm{~min}$ ) to collect plasma. Urinary and plasmatic levels of creatinine were measured using an automatic analyzer (Roche Diagnostics Limited, Rotkreuz Switzerland). Creatinine clearance $(\mathrm{CrCl})$ was calculated using the formula: $\mathrm{CrCl}=(\mathrm{V}$ $\min \times \mathrm{uCr}) / \mathrm{sCr}$, where $\mathrm{V}$ min is urinary volume per minute, $\mathrm{uCr}$ and $\mathrm{sCr}$ are, respectively, urinary and serum creatinine (Darling and Morris, 1991). Urinary KIM-1 was determined by sandwich enzyme-linked immunosorbent assay (ELISA) (R\&D Systems, Inc-Cat. RKM100). The detection range for KIM-1 was $7.8-500 \mathrm{pg} / \mathrm{mL}$ and the intra-assay coefficient of variation is $3.2 \%$ and expressed as ratios to urinary creatinine concentration.

\subsection{Culture of tubular kidney cells assays}

LLC-MK2 cells (Hull et al., 1962), proximal tubular epithelial cells, were kindly donated by the Department of Biochemistry of São Paulo University and cultured in Dulbecco's modified Eagle's medium (DMEM, Invitrogen, USA), supplemented with 10\% fetal bovine serum (FBS) and antibiotics in standard conditions until confluence was reached. The cells were plated at $10^{5}$ cell/mL in 96-well plates for $24 \mathrm{~h}$ and treated with BinsV at several concentrations (200; 100; 50; 25; $12.5 ; 6.25 ; 3.12 \mu \mathrm{g} / \mathrm{mL}$ ). After $24 \mathrm{~h}$, cell viability recovery was measured by MTT assay (Vanden Berghe et al., 2013).

\subsection{Multiparametric flow cytometry analysis to assess cell death mechanism}

LLC-MK2 cells were plated and treated with BinsV at their IC50 concentrations for $24 \mathrm{~h}$ of exposure, at $37^{\circ} \mathrm{C}$ and $5 \%$ of $\mathrm{CO}_{2}$. Next, these cells were dislocated, washed and stained with FITC-labeled annexin V (AX) and 7-aminoactinomycin D (7-AAD), according to the manufacturer's instructions (BD Pharmingen, California, USA) aiming at identifying cell death mechanism either by apoptosis or necrosis, respectively. In separate experiments, the loss of mitochondrial transmembrane potential and the outburst of reactive oxygen species (ROS) were also investigated. LLC-MK2 cells were treated with BinsV (IC50) for $24 \mathrm{~h}$ and stained with Rhodamine $123(10 \mu \mathrm{g} / \mathrm{mL})$ or DCFHDA $(20 \mathrm{mMol} / \mathrm{L})$, according to the manufacturer's instructions (Sigma-Aldrich $^{\mathrm{TM}}$, St. Louis, USA), respectively. At the end of each incubation period, the cells were washed and run in a FACSCalibur flow cytometer (Becton-Dickinson, San Jose, CA). A total of 10,000 live events were analyzed using the Cell Quest software and the results were established by determining the fold change (treated/non-treated cell ratio) of the geometric mean of fluorescence. Cells without treatment with BinsV were used as controls and experiments were carried out in triplicate.

\subsection{Statistical analysis}

All data were expressed as mean \pm standard error mean (SEM). For statistical comparisons between groups, Student's $t$-test or one-way and/or two-way ANOVA were used, followed by Bonferroni test. Significance was set at $\mathrm{p}<0.05$. Statistical analyses were performed using GraphPad Prism5.0 (USA).

\section{Results and discussion}

AKI has been described in injury by toxins from a variety of animals (Sitprija and Sitprija, 2012). The nephrotoxicity of $B$. insularis venom has been previously described by our group (Braga et al., 2006; Mello et al., 2014), but in vivo studies have not been performed. In this study, we evaluated the nephrotoxic effect of this venom in mice through histological analyses, determination of TBARS and GSH levels. We also 

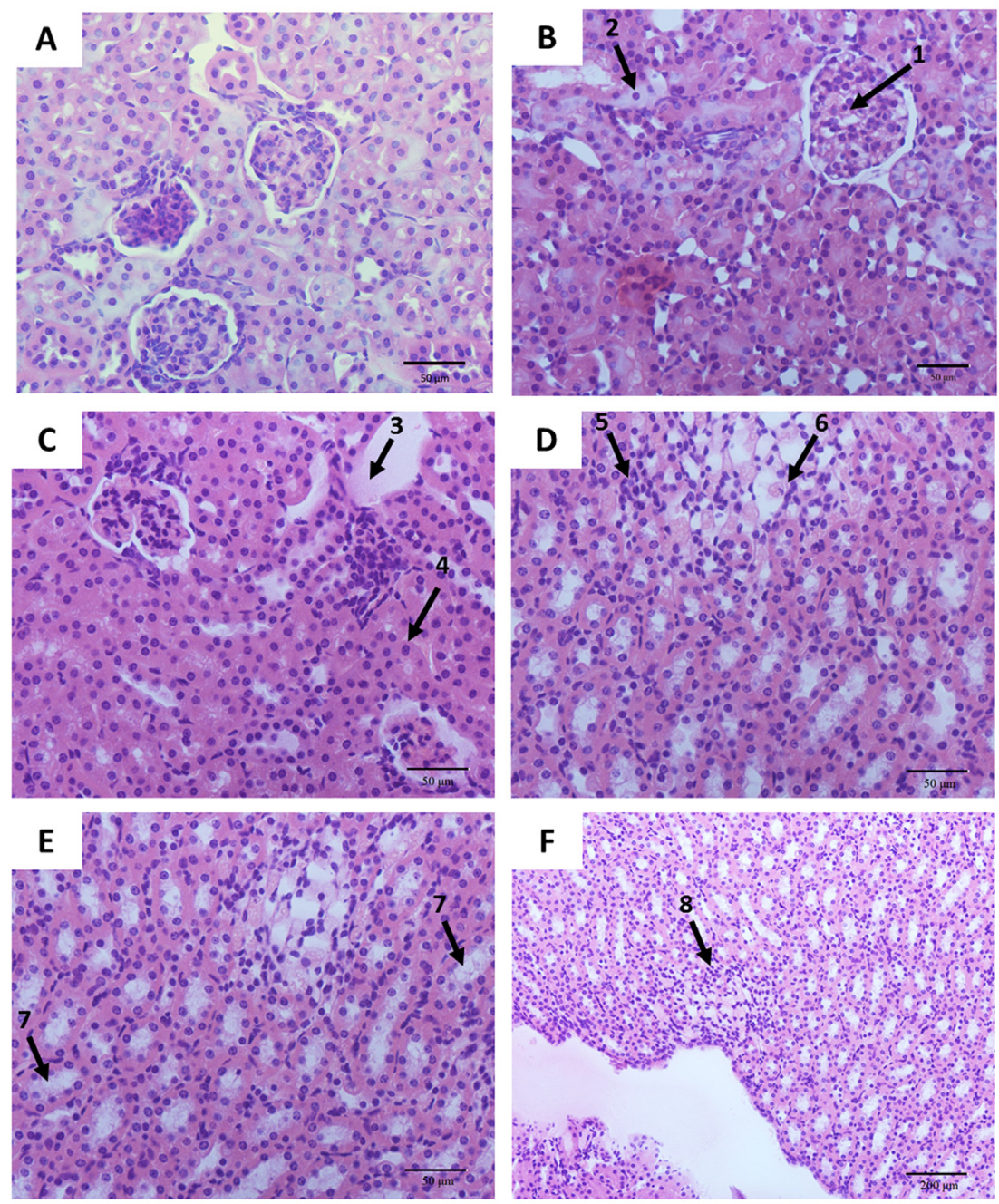

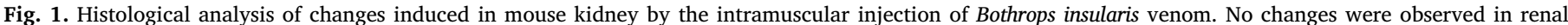

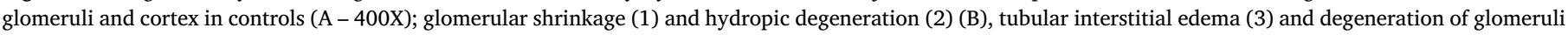

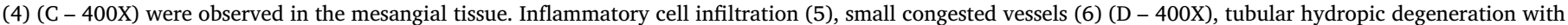
secretion of Tamm-Horsfall protein $(7)(\mathrm{E}-400 \mathrm{X})$ and presence of inflammatory cells in interstitium in the cord (8) were observed (F - 100X). H/E.

performed measurement of biochemical parameters, assessing KIM-1 as a biomarker in the early diagnosis and risk stratification of AKI, evaluating the cytotoxicity of BinsV on LLC-MK2 proximal tubular renal cells.

A previous study that demonstrated the histopathological changes induced in avian kidney by the intramuscular injection of Bothrops insularis venom resulted in significant structural damage to the kidneys of chicks, indicating that the venom acted on the renal tubules and glomeruli (da Cruz Höfling et al., 2001). In this study, the histological analyses of the effects of an intramuscular injection of BinsV showed mesangial tissue swelling, glomerular shrinkage and degeneration, hydropic degeneration, tubular interstitial edema and renal cortex swelling. In the medulla, inflammatory cell infiltration, small congested vessels, tubular hydropic degeneration with Tamm- Horsfall protein secretion and presence of inflammatory cells in the interstitium were observed, indicating Acute Kidney Injury (AKI) (Fig. 1).

The kidney is a highly vascularized organ and thus, it is vulnerable to toxin injury. Multiple factors including hemodynamic changes, inflammatory reactions and nephrotoxic effects of venoms can be involved with this injury (Sitprija and Sitprija, 2012). Inflammation plays an important role in the development of snake venom toxicity. BinsV was previously described as its inflammatory effect (Menezes et al., 2016), and in this work we observed the accumulation of inflammatory cells on kidney of mice treated with BinsV.

Overall, AKI diagnosis has used creatinine levels as its biomarker. However, it is not a specific, sensible and early predictor of damage. Significant nephron damage is necessary to obtain an increase in plasma creatinine levels and creatinine could be reabsorbed or secreted in the renal tubule, under- or overestimating the glomerular filtration rate. Thus, we have sought to establish a sensitive detection biomarker and with high specificity (Bellomo et al., 2012). KIM-1 meets the requirements for an ideal marker for proximal tubular damage. In this study, we did not observe an increase in urinary creatinine (Fig. 2A), but KIM-1 release was observed in the urine of mice with AKI induced by inoculation of BinsV (Fig. 2B). Furthermore, Pearson's correlation also showed that KIM-1 had a directly proportional positive correlation with plasma creatinine (Fig. 2C).

The tissue changes indicate mild changes with some tubular epithelial cells were injured. In contrast, serum creatinine levels were increased to $1.18 \mathrm{mg} / \mathrm{dL}$ while the basal creatine levels were $0.4 \mathrm{mg} / \mathrm{dL}$, suggesting severe injury. Bothrops venom causes decrease in the blood pressure (Sciani and Pimenta, 2017) and functional injuries such as vasospasm might be existed on the kidney. Also, BinsV might induce muscle injures as the other toxins (White, 2000) and this could increase serum creatinine, which are unspecific marker (Debelmas et al., 2018). They might be the reasons of the discrepancy of serum creatinine and 

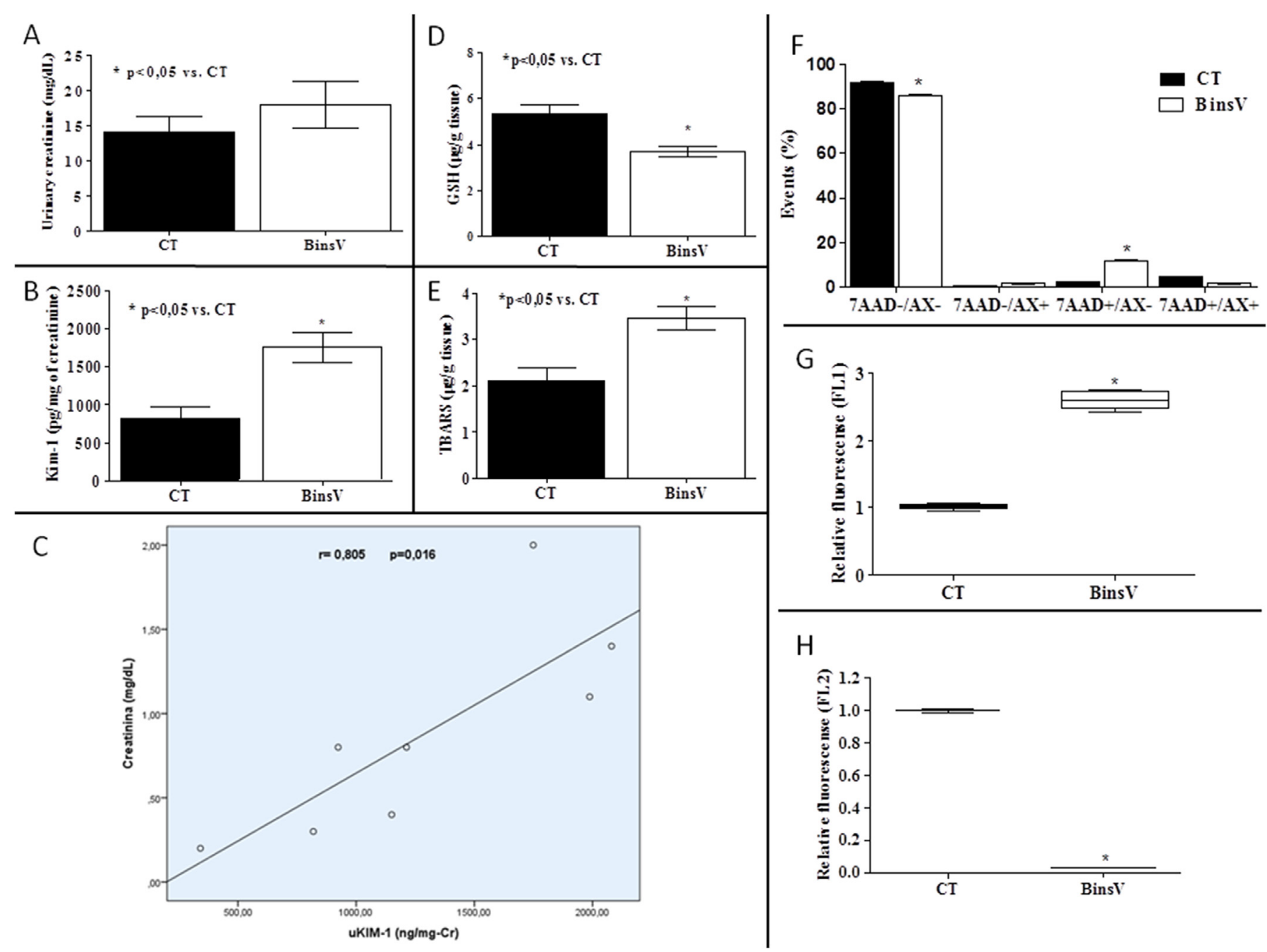

$\mathrm{H}$

Fig. 2. Bothrops insularis venom (BinsV) effects after its intramuscular injection in mice (A-E) and its incubation with LLC-MK2 proximal tubular cells after $24 \mathrm{~h}$ (F-I). (A) Urinary creatinine in mice. (B) Urinary Kidney Injury Molecule (KIM-1) levels in mice. (C) Pearson's correlation of KIM-1 x plasma creatinine in mice. (D) Evaluation of reduced glutathione (GSH) and (E) malondialdehyde (MDA) in mouse kidney tissue. Results are shown as mean \pm SEM; *p < 0.05 compared to the vehicle control groups. Analysis of cell death mechanism by flow cytometry after treatment with IC50 of BinsV after $24 \mathrm{~h}$ of incubation: (F) Apoptosis and necrosis evaluation by 7AAd and AX labeling (G) Production of ROS by DCF-DA assay. (H) Mitochondrial transmembrane potential analysis by rhodamine 123 labeling. The data expressed as fluorescence ratio are related to control \pm SEM. $* \mathrm{p}<0.05$ vs. group control.

renal pathologies observed in this study. These findings also corroborate with the needing of more specific biomarkers of AKI in this case, such KIM-1.

KIM-1 is a transmembrane glycoprotein consisting of an immunoglobulin and a mucin domain, working as a phosphatidylserine receptor, which is externalized during cell death. The ectodomain of KIM-1 is cleaved by metalloproteinases during the formation of apoptotic bodies and oxidized lipids related to oxidative stress (Lahoud et al., 2015).

The increase in ROS after damage could cause cell death, but the antioxidant system consisting of catalase, superoxide dismutase and glutathione peroxidase act against ROS (Razvickas et al., 2013). The unbalance of antioxidant defenses and ROS formation can cause a disruption in the mitochondrial electron transport chain, deregulating oxidative phosphorylation. In this study, glutathione peroxidase decreased (Fig. 2D) in the renal tissue of mice inoculated with BinsV.

TBARS, here expressed mainly by MDA, are markers of oxidative stress, more specifically of lipid oxidation. In this study, we observed the increase in MDA levels (Fig. 2E) related to the AKI onset, as shown previously by Da Costa et al. (2015), Sampaio et al. (2016) and Kadkhodaee et al. (2014). MDA and GSH levels were measured in renal tissue to indirectly assess oxidative stress. Reactive oxygen species can result in further renal damage by inducing tubular cell death, inflammation and mitochondrial damage (Zhou et al., 2008; Ye et al., 2010).

BinsV was also characterized by its direct nephrotoxicity in MDCK tubular distal cells (Mello et al., 2014) and electrolyte transport alterations in an isolated renal perfusion model (Braga et al., 2008). The proximal tubule is particularly susceptible to injury, attributed in part to a sensitive, high metabolic rate and a higher exposure to intracellular concentrations of toxic compounds. This level of exposure is caused mainly by a high level of blood flow to the kidney (Crean et al., 2015). Thus, we evaluated BinsV toxicity in proximal tubular renal LLC-MK2 cells and it showed an IC50 of $116.2 \mu \mathrm{g} / \mathrm{mL}$.

Aiming to evaluate the cell death pathway in LLC-MK2 cells, cytometry flow assays were performed, using 7-AAD and AX labelling to evaluate membrane damage and phosphatidylserine externalization. Additionally, Rhodamine 123 was used to evaluate mitochondrial transmembrane potential and DCF-DA to evaluate ROS production. It An increase in cell labeling with 7AAD + /AX (Fig. 2F) was observed, suggesting membrane damage and necrosis; ROS overproduction (Fig. 2G), corroborated these findings. The associated loss of mitochondrial transmembrane potential (Fig. $2 \mathrm{H}$ ) could indicate necrosis cell death pathway and could be associated to increase of ROS and Kim- 
1 ectodomain externalization (Gandhi et al., 2014).

Oxidative stress is associated with snakebite-induced renal damage (de Morais et al., 2013; Mello et al., 2014; Marinho et al., 2015), which could be evaluated in vivo through KIM-1 release in urine. Altogether, KIM-1 is an early biomarker of AKI diagnosis that could be used as a tool to evaluate early renal damage induced by snakebites.

\section{Transparency document}

Transparency document related to this article can be found online at http://dx.doi.org/10.1016/j.toxicon.2018.06.074.

\section{References}

Bellomo, R., Kellum, J.A., Ronco, C., 2012. Acute kidney injury. Lancet 330, 756-766. Bonventre, J., 2014. Kidney injury molecule-1: a translational journey. Trans. Am. Clin. Climatol. Assoc. 125, 293-299.

Braga, M.D., Martins, A.M., Amora, D.N., De Menezes, D.B., Toyama, M.H., Toyama, D.O., Marangoni, S., Barbosa, P.S., De Sousa Alves, R., Fonteles, M.C., Monteiro, H.S., 2006. Purification and biological effects of C-type lectin isolated from Bothrops insularis venom. Toxicon 47, 859-867.

Braga, M.D., Martins, A.M., Amora, D.N., De Menezes, D.B., Toyama, M.H., Toyama, D.O., Marangoni, S., Barbosa, P.S., De Sousa Alves, R., Fonteles, M.C., Monteiro, H.S., 2007. Purification and biological activity of the thrombin-like substance isolated from Bothrops insularis venom. Toxicon 49, 329-338.

Braga, M.D., Martins, A.M., Amora, D.N., De Menezes, D.B., Toyama, M.H., Toyama, D.O., Marangoni, S., Barbosa, P.S., De Sousa Alves, R., Fonteles, M.C., Monteiro, H.S., 2008. Purification and biological effects of L-amino acid oxidase isolated from Bothrops insularis venom. Toxicon 51, 199-207.

Crean, D., Bellwon, P., Aschauer, L., Limonciel, A., Moenks, K., Hewitt, P., Schmidt, T., Herrgen, K., Dekant, W., Lukas, A., Bois, F., Wilmes, A., Jennings, P., Leonard, M.O., 2015. Development of an in vitro renal epithelial disease state model for xenobiotic toxicity testing. Toxicol. Vitro 30, 128-137.

Darling, I.M., Morris, M.E., 1991. Evaluation of "true" creatinine clearance in rats reveals extensive renal secretion. Pharm. Res. 8, 1318-1322.

Da Costa, M.F., Libório, A.B., Teles, F., Martins, C.D.A.S., Soares, P.M., Meneses, G.C., et al., 2015. Red propolis ameliorates ischemic-reperfusion acute kidney injury. Phytomedicine 22, 787-795.

Da Cruz Hofling, M.A., Paronetto, C.C., Cogo, J.C., Rodriguessimioni, L., D'abreu, A.C., 2001. Histopathological changes in avian kidney caused by Bothrops insularis (jararaca ilhoa) venom and a phospholipase A2-containing fraction. Histol. Histopathol. 16, 185-195.

Debelmas, A., Benchetrit, D., Galanaud, D., Khonsari, R.H., 2018. Case 251: nontraumatic drug-associated rhabdomyolysis of head and neck muscles. Radiology 286 1088-1092.

Gandhi, R., Yi, J., Ha, J., Shi, H., Ismail, O., Nathoo, S., Bonventre, J.V., Zhang, X., Gunaratnam, L., 2014. Accelerated receptor shedding inhibits kidney injury molecule-1 (KIM-1)-mediated efferocytosis. Am. J. Physiol. Ren. Physiol. 307, 205-221.

Hull, R.N., Cherry, W.R., Tritch, O.J., 1962. Growth characteristics of monkey kidney cell strains llc-mk1, llc-mk2, and llc-mk2(nctc-3196) and their utility in virus research. J. Exp. Med. 115, 903-918.

Kadkhodaee, M., Najafi, A., Seifi, B., 2014. Classical and remote post-conditioning effects on ischemia/reperfusion-induced acute oxidant kidney injury. Int. J. Surg. 12, 1162-1166.

Lahoud, Y., Hussein, O., Shalabi, A., Nativ, O., Awad, H., Khamaisi, M., et al., 2015.
Effects of phosphodiesterase-5 inhibitor on ischemic kidney injury during nephron sparing surgery: quantitative assessment by NGAL and KIM-1. World J. Urol. 33, 2053-2062.

Marinho, A.D., Morais, I.C., Lima, D.B., Jorge, A.R., Jorge, R.J., Menezes, R.R., Mello, C.P., Pereira, G.J., Silveira, J.A., Toyama, M.H., Orzáez, M., Martins, A.M., Monteiro, H.S., 2015. Bothropoides pauloensis venom effects on isolated perfused kidney and cultured renal tubular epithelial cells. Toxicon 108, 126-133.

Mello, C.P., Morais, I.C., Menezes, R.R., Pereira, G.J., Torres, A.F., Lima, D.B., Pereira, T.P., Toyama, M.H., Monteiro, H.S., Smaili, S.S., Martins, A.M., 2014. Bothropoides insularis venom cytotoxicity in renal tubular epithelia cells. Toxicon 88, 107-114.

Menezes, R.R., Mello, C.P., Lima, D.B., Tessarolo, L.D., Sampaio, T.L., Paes, L.C., Alves, N.T., Assis Junior, E.M., Lima Junior, R.C., Toyama, M.H., Martins, A.M., 2016. Involvement of nitric oxide on bothropoides insularis venom biological effects on murine macrophages in vitro. PLoS One 14, e0151029.

Mihara, M., Uchiyama, M., Fukuzawa, K., 1980. Thiobarbituric acid value on fresh homogenate of rat as a parameter of lipid peroxidation in aging, CCl4 intoxication, and vitamin E deficiency. Biochem. Med. 23, 302-311.

de Morais, I.C., Torres, A.F., Pereira, G.J., Pereira, T.P., Pessoa Bezerra de Menezes, R.R., Mello, C.P., Coelho Jorge, A.R., Bindá, A.H., Toyama, M.H., Monteiro, H.S., Smaili, S.S., Martins, A.M., 2013. Bothrops leucurus venom induces nephrotoxicity in the isolated perfused kidney and cultured renal tubular epithelia. Toxicon 61, 38-46.

Queiroz, G.P., Pessoa, L.A., Portaro, F.C.V., Furtado, M.F.D., Tambourgi, D.V., 2008. Interspecific variation in venom composition and toxicity of Brazilian snakes from Bothrops genus. Toxicon 52, 842-851.

Razvickas, C.V., Borges, F.T., De Oliveira, A.S., Schor, N., Boim, M.A., 2013. Efeito da hipóxia e reoxigenação na resposta à angiotensina II em células mesangiais in vitro. J. Bras. Nefrol. 35, 4.

Sampaio, T.L., Menezes, R.R., da Costa, M.F., Meneses, G.C., Arrieta, M.C., Chaves Filho, A.J., de Morais, G.B., Libório, A.B., Alves, R.S., Evangelista, J.S., Martins, A.M., 2016. Nephroprotective effects of (-)- $\alpha$-bisabolol against ischemic-reperfusion acute kidney injury. Phytomedicine 23, 1843-1852.

Sciani, J.M., Pimenta, D.C., 2017. The modular nature of bradykinin-potentiating pep tides isolated from snake venoms. J. Venom. Anim. Toxins Incl. Trop. Dis. 23, 45

Sgrignolli, L.R., Mendes, G.E.F., Carlos, C.P., Burdmann, E.A., 2011. Acute kidney injury caused by Bothrops snake venom. Nephron Clin. Pract. 119, 131-137.

Sitprija, V., Sitprija, S., 2012. Renal effects and injury induced by animal toxins. Toxicon 5, 943-953.

Valente, R.H., Guimarães, P.R., Junqueira, M., Neves-Ferreira, A.G., Soares, M.R., Chapeaurouge, A., Trugilho, M.R., León, I.R., Rocha, S.L., Oliveira-Carvalho, A.L., Wermelinger, L.S., Dutra, D.L., Leão, L.I., Junqueira-De-Azevedo, I.L., Ho, P.L., Zingali, R.B., Perales, J., Domont, G.B., 2009. Bothrops insularis venomics: a proteomic analysis supported by transcriptomic- generated sequence data. J. Proteomics $72,241-255$.

Vijayan, A., Faubel, S., Askenazi, D.J., Cerda, J., Fissell, W.H., Heung, M., Humphreys, B.D., Koyner, J.L., Liu, K.D., Mour, G., Nolin, T.D., Bihorac, A., 2016. Clinical use of the urine biomarker [TIMP-2] $\times$ [IGFBP7] for acute kidney injury risk assessment. Am. J. Kidney Dis. 68, 19-28.

Vanden Berghe, T., Grootjans, S., Goossens, V., Dondelinger, Y., Krysko, D.V., Takahashi, N., Vandenabeele, P., 2013. Determination of apoptotic and necrotic cell death in vitro and in vivo. Methods 61, 117-129.

White, J., 2000. Bites and stings from venomous animals: a global overview. Ther. Drug Monit. 22, 65-68.

Ye, T.M., Sun, L.N., Su, F., Shen, J., Wang, H.P., Ye, Z.G., Xia, Q., 2010. Study of the effects of Auricularia auricular polysaccharide on local ischemia/reperfusion injury in rat. Zhongguo Ying Yong Sheng Li Xue Za Zhi 26, 423-426.

Zhou, Y., Vaidya, V.S., Brown, R.P., Zhang, J., Rosenzweig, B.A., Thompson, K.L., Miller, T.J., Bonventre, J.V., Goering, P.L., 2008. Comparison of kidney injury molecule-1 and other nephrotoxicity biomarkers in urine and kidney following acute exposure to gentamicin, mercury, and chromium. Toxicol. Sci. 101, 159-170. 